University of Nebraska - Lincoln

DigitalCommons@University of Nebraska - Lincoln

Faculty Papers and Publications in Animal

Science

Animal Science Department

4-28-2005

\title{
Influence of breed, heterozygosity, and disease incidence on estimates of variance components of respiratory disease in preweaned beef calves
}

G. D. Snowder

USDA-ARS, U.S. Meat Animal Research Center

L. Dale Van Vleck

University of Nebraska-Lincoln, dvan-vleck1@unl.edu

L. V. Cundiff

USDA-ARS, U.S. Meat Animal Research Center

G. L. Bennett

USDA-ARS, U.S. Meat Animal Research Center, gary.bennett@ars.usda.gov

Follow this and additional works at: https://digitalcommons.unl.edu/animalscifacpub

Part of the Animal Sciences Commons

Snowder, G. D.; Van Vleck, L. Dale; Cundiff, L. V.; and Bennett, G. L., "Influence of breed, heterozygosity, and disease incidence on estimates of variance components of respiratory disease in preweaned beef calves" (2005). Faculty Papers and Publications in Animal Science. 212.

https://digitalcommons.unl.edu/animalscifacpub/212

This Article is brought to you for free and open access by the Animal Science Department at DigitalCommons@University of Nebraska - Lincoln. It has been accepted for inclusion in Faculty Papers and Publications in Animal Science by an authorized administrator of DigitalCommons@University of Nebraska - Lincoln. 


\title{
Influence of breed, heterozygosity, and disease incidence on estimates of variance components of respiratory disease in preweaned beef calves
}

\author{
G. D. Snowder*1, L. D. Van Vleck†, L. V. Cundiff*, and G. L. Bennett* \\ *ARS, USDA, U.S. Meat Animal Research Center, Clay Center, NE 68933; and †ARS, USDA, \\ U.S. Meat Animal Research Center, Lincoln, NE 68583
}

\begin{abstract}
The objective of this study was to characterize genetic and environmental factors influencing bovine respiratory disease (BRD) in beef cattle. Records from nine purebred and three composite breeds and a variety of $\mathrm{F}_{1}$ and three-way crosses, including the progeny of 12 additional different sire breeds produced over a 20-yr period (1983 to 2002), were evaluated for breed and heterozygosity effects on the observed incidence of BRD. Heterozygosity fractions for calves and dams were defined by generalized breed origins: British, Continental, and tropically adapted. Variance components were estimated for each pure and composite breed, and across all breeds and crossbreeds. The effect of incidence of observed BRD was determined by comparing groups of low and high years of incidence. Respiratory disease in this herd followed a standard epidemiological pattern of initial introduction, reaching an epidemic stage at 70 to $170 \mathrm{~d}$ of age, followed by a period of rapid decrease to weaning. Estimates of heritability of incidence of BRD were low, ranging from 0.00 to 0.26 , with overall estimates of 0.07 and 0.19 depending on
\end{abstract}

the data set analyzed. The highest incidence of BRD in preweaned calves occurred in the Braunvieh breed $(18.8 \%)$. The genetic correlation between the direct and maternal genetic effects was generally large and negative, suggesting dams genetically superior for resisting BRD raise calves that are more susceptible. Perhaps maternally superior dams provide passive immunity to their calves, which delays the development of the calves' direct immune system, making them more prone to $\mathrm{BRD}$ during the preweaning period. Heterozygosity of calves decreased the incidence of BRD compared with purebred cattle. Calves that were Continental $\times$ British or tropically adapted $\times$ British breeds had a lower incidence of BRD than did calves of British $\times$ British breeds. As the annual incidence of BRD increased, there was an associated increase in the heritability estimate. The estimated heritability based on an underlying continuous scale was large $\left(h^{2}=0.48\right)$, inferring response to selection for BRD resistance could be large if the phenotype for $\mathrm{BRD}$ resistance was known.

Key Words: Disease Resistance, Growth, Heritability, Survival

(C2005 American Society of Animal Science. All rights reserved.

J. Anim. Sci. 2005. 83:1247-1261

\section{Introduction}

Bovine respiratory disease (BRD) is the most common and costly disease of beef cattle in the United States. The national mortality rate of beef cows associated with BRD is 6.0\% (NAHMS, 1997). Bovine respiratory disease is a complex of diseases characterized by many types of infection, each having its own causes, clinical signs, and economic implications. Prevalent microbial causes of BRD (Ellis, 2001) are of viral (infectious bovine rhinotracheitis, bovine viral diarrhea, bovine respiratory syncytial, and parainfluenza type 3), bacterial (Mannheimia haemolytica, Pasteurella mul-

\footnotetext{
${ }^{1}$ Correspondence: P.O. Box 166 (phone: 402-762-4167; fax: 402762-4173; e-mail: snowder@email.marc.usda.gov).

Received July 20, 2004.

Accepted March 2, 2005.
}

tocida, Haemophilus somnus), and mycoplasmal origins.

Predisposing causes for BRD (Callan and Garry, 2002) in preweaned calves are generally concurrent, often synergistic, and include age, stress, immunological background, dehydration, nutritional stress, and inadequate passive immunoglobulin transfer. Environmental risk factors include climate, ambient temperature, dust particles, exposure to noxious gases, stocking density, humidity, and ventilation. Epidemiological factors include microbial agent(s), mode of transmission, parasite density dependence, infectious period, latent and carrier period, virulence, and so on. Economic expenses associated with subclinical and clinical infection are decreased weight gains, veterinarian costs, and death. Incidence of BRD can be decreased by improving management practices, antibiotics, and vaccines.

The heritability estimate for resistance to BRD is low, approximately $0.10 \pm 0.02$ (Muggli-Cockett et al., 
1992). Breeds may differ significantly in observed preweaning BRD incidence (Muggli-Cockett et al., 1992), although whether these differences are genetically influenced is unknown. Crossbred cattle are widely assumed to be healthier than purebreds, but literature supporting this assumption was not found. Therefore, the objective of this study was to determine effects of genetic factors and of level of disease incidence on resistance and/or tolerance to BRD.

\section{Materials and Methods}

\section{Data}

Birth and health records of 110,412 calves from the U.S. Meat Animal Research Center (MARC), Clay Center, NE, over a 20-yr period (1983 to 2002) were evaluated. Calving typically began in mid-February and continued until early June, averaging a period of $101 \mathrm{~d}$. Calves were born in an open pasture. Management, pasture description, and supplemental feeding of cows and calves were described previously by Cundiff et al. (1998). At birth, calves were weighed, dehorned, ear tagged, and tattooed for identification, and their navels were treated with iodine. Most bull calves were castrated by surgical excision. At approximately 42-d of age, when cows were placed into breeding pastures, calves were vaccinated with an eight-way clostridial and a five-way leptospirial vaccine. At approximately 165-d of age, calves were given booster vaccinations of clostridial and leptospirial vaccines and a modified live vaccine for infectious bovine rhinotracheitis, parainfluenza-3, and bovine viral diarrhea. Additional treatments may have been administered to calves diagnosed with BRD and/or any other ailment. For calves expressing clinical signs of $\mathrm{BRD}$, the calf's age, weight, and severity of clinical expression were considered in determining the appropriate treatment. Treatments for BRD included administration of one or more antibiotics (oxytetracycline, ceftiofur, florfenicol, ampicillin, and sulfadimethoxine) to the calf. Calves with BRD were checked daily and may have received several antibiotic therapy treatments, as determined by the veterinarian and/or technical staff. Antibiotics were not routinely administered to calves before weaning.

Calves were monitored daily by the staff veterinarian and/or beef cattle research technicians for health from birth until weaning at an average age of $194 \mathrm{~d}$. Diseases were detected by physical examination, necropsy, or laboratory analyses and appropriately coded. Typical clinical BRD symptoms for preweaned calves included one or more of the following: fever, rapid breathing, repetitive coughing, nasal and/or eye discharge, diarrhea, dehydration, and appetite depression. Disease codes related to BRD were combined. The majority of the BRD classifications were from codes for "pneumonia" and "respiratory disease" (84 and 13\%, respectively). Additional disease codes included for BRD were bronchitis, emphysema, pleuritis, pulmonary adeno- matosis, upper respiratory infection, and pleural fibrosis. Because such diseases may be interpreted as BRD by producers, it was appropriate to include them as $\mathrm{BRD}$ in the field data set. The recoded binary classification listed calves as either healthy (Code $=200)$ or affected by BRD (Code = 100). Records also included calves that died due to BRD causes. To avoid multiple measurements on the same calf resulting from lingering respiratory disease or reinfection, only the initial observed infection during the preweaning period was considered.

Classification could not be made as to whether an animal was tolerant or resistant to BRD. Tolerance is defined as the ability of an infected animal to show little or no measurable detrimental effect of the disease. Resistance is the ability of the animal to resist infection or control the lifecycle of the infecting microbe. In this study, the term "resistant" was used to describe an animal that was not detected with clinical symptoms of $\mathrm{BRD}$, without regard for whether the animal was truly tolerant, resistant, or not exposed to BRD-causing organisms. Therefore, incidence of clinical BRD was the actual trait measured.

Two related sets of data were analyzed. The first set comprised nine pure breeds (Angus, Braunvieh, Charolais, Gelbvieh, Hereford, Limousin, Pinzgauer, Red Poll, and Simmental) and three composite breeds (MARC I, MARC II, and MARC III). These animals were part of a large germplasm utilization study conducted to evaluate heterosis retention and use of breed differences in composite populations (Gregory et al., 1991b, 1999). Most purebred and composite populations were present in each of the $20 \mathrm{yr}$, except for Braunvieh (present from 1983 to 1992), Red Poll (present from 1983 to 1993), Simmental (present from 1983 to 1997), Limousin (present from 1983 to 1992), and Pinzgauer (present from 1983 to 1993). No single purebred or composite population was represented for less than $10 \mathrm{yr}$. Because an upgrading breeding program had been practiced to develop a few of the purebred groups, animals with seven-eighths and fifteen-sixteenths genes from that breed were included in their respective purebred group only when individual breeds were analyzed or when levels of heterozygosity were not included in the statistical model.

The second data set included crossbred groups. Animals in this data set were from two research projects: 1) the previously described germplasm utilization project; and 2) the germplasm evaluation project. The latter project was a crossbreeding evaluation study. Crossbred calves were produced in Cycle IV (Cundiff et al., 1998), Cycle V (Freetly and Cundiff, 1997; Wheeler et al., 2001), and Cycle VI (Cundiff et al., 2001) of the Cattle Germplasm Evaluation Program at MARC. From Cycle IV, progeny of Hereford and Angus dams sired by four British breeds (Hereford, Angus, Galloway, and Shorthorn), three Continental European breeds (Salers, Piedmontese, and Charolais), one American breed (Longhorn, grouped with Continental Euro- 
pean breeds for this study because of its ancestral origin, Spain and Portugal), and one tropically adapted Bos indicus breed (Nellore) produced in 1986 to 1990 were included in the analyses. Also included were the progeny produced from 1988 to 1997 to evaluate the maternal performance of the Cycle IV $\mathrm{F}_{1}$ cross females when they were raising calves by Red Poll sires at $2 \mathrm{yr}$ of age and by Simmental sires at 3 to $8 \mathrm{yr}$ of age. These crossbred progeny produced from 1988 to 1997 also were included in the analysis. In Cycle V, $\mathrm{F}_{1}$ cross progeny of Hereford, Angus, and MARC III dams sired by two British breeds (Hereford and Angus), two Continental European breeds (Piedmontese and Belgian Blue, all sires were homozygous for an inactive myostatin allele that causes muscle hypertrophy, Smith et al., 1997), and two tropically adapted Bos indicus breeds (Brahman and Boran) produced in 1992 to 1994 were included in the analysis. Also included were the progeny produced from 1994 to 2002 by the Cycle $\mathrm{V} \mathrm{F}_{1}$ cross females to evaluate maternal performance when they were raising calves by Red Poll sires at $2 \mathrm{yr}$ of age, and by Charolais or $\mathrm{F}_{1}$ Belgian Blue sires (Belgian Blue $\times$ Angus, Belgian Blue $\times$ Hereford, and Belgian Blue $\times$ MARC III) sires at 3 to $8 \mathrm{yr}$ of age. In Cycle VI, $\mathrm{F}_{1}$ cross progeny of Hereford, Angus, and MARC III dams sired by two British breeds (Hereford and Angus) and two Continental European breeds (Friesian, and NSR = Norwegian Red/Swedish Red and White, considered as one breed in this study because of an open-herd book policy between the two breeds in Norway and Sweden), were produced from 1997 to 1998. Also included were the progeny produced from 1999 to 2002 by the Cycle VI $F_{1}$ cross females to evaluate maternal performance when they produced progeny by MARC III sires at $2 \mathrm{yr}$ of age and by Charolais sires at 3 to $5 \mathrm{yr}$ of age. This data set was analyzed to estimate effects of heterozygosity and to compare a larger number of breeds for incidence of BRD.

The data were edited to remove possible incorrect records. Calves subjected to research protocols such as varying nutritional regimens, hormonal therapy, and antibody challenges, which may have influenced its or its dam's health or performance were removed $(\mathrm{n}=$ $34,973)$. Only records of spring- and single-born calves that survived for at least $3 \mathrm{~d}$ postpartum were included. Approximately $2.5 \%$ of all spring born calves died within $3 \mathrm{~d}$ of birth. Bull calves with cryptorchid testes were removed. Calves with an unknown dam $(n=576)$ or born to a yearling heifer $(n=4)$ were deleted. Calves that died of a disease or other causes thought not to be related to BRD before weaning were not included. The two edited data sets had totals of 59,719 (germplasm utilization study of nine purebreds and three composite groups) and 75,439 records (germplasm utilization study and additional crossbred calves from the germplasm evaluation study).

Information recorded for the calves included day of birth, weight at birth, age at weaning, age when BRD was first detected, and sex (male, including bulls and
Table 1. Number of multisire-mated pasture groups and total number of bulls and calves by sire breed

\begin{tabular}{lcrr}
\hline \hline Sire breed & $\begin{array}{c}\text { No. of } \\
\text { groups }\end{array}$ & $\begin{array}{c}\text { No. of } \\
\text { bulls }\end{array}$ & $\begin{array}{r}\text { No. of } \\
\text { calves }\end{array}$ \\
\hline Angus & 31 & 150 & 2,193 \\
Charolais & 26 & 182 & 2,933 \\
Hereford & 5 & 14 & 179 \\
Gelbvieh & 5 & 33 & 540 \\
Red Poll & 12 & 127 & 2,013 \\
Simmental & 24 & 262 & 3,625 \\
MARC II & 10 & 38 & 252 \\
MARC III & 85 & 595 & 6,995 \\
Total & 198 & 1,4011 & 18,740 \\
\hline
\end{tabular}

castrates, or female). Calving difficulty (dystocia) was subjectively coded for each calf at birth on a scale of 1 to 7 with larger numbers representing increased difficulty ( 1 = unassisted; 2 = little difficulty with hand assistance; 3 = little difficulty with mechanical calf puller; $4=$ slight difficulty, assisted with calf puller; $5=$ moderate difficulty with assistance; 6 = major difficulty, with more than $30 \mathrm{~min}$ of assisted delivery; 7 = caesarean birth). Ninety-three percent of all births were scored with no or little difficulty (Codes 1, 2, or 3). Age of dam was grouped into five classifications: 2, 3, 4, 5 through 7 , and $8 \mathrm{yr}$ or older. Year of record, sex of calf, and age of dam were coded as a single three-way interaction variable. Breed composition of calf, dam, and sire also were recorded.

\section{Statistical Procedures}

Because individual sires of calves born in multisired pastures were unknown in 8 of the 12 breeds, groups within purebred sired pastures were created and handled computationally as Westell groups (Westell et al., 1988). Only pasture breeding groups with at least 10 offspring were included, decreasing the number of multisire-mated pasture groups from 209 to 198 (Table 1 ). The number of bulls placed in a pasture group ranged from 2 to 22 , with an average of 7.9 bulls. The average number of offspring among multisired pasture groups was 91, and ranged from 10 to 271 .

The pedigree file used to calculate the relationship matrix for the edited data set consisted of 72,806 different animals born between 1968 and 2002, including 2,481 different sires (not including 198 multi-sired pasture groups) and 20,796 different dams. The number of animals with an estimable inbreeding coefficient was 14,780. Their average inbreeding coefficient was $2.9 \%$. Numbers of sires and dams with calves by breed are reported in Table 2 . Breeds represented by a small number of founder sires with no founder dams were considered in analyses using generalized heterozygosity groups and overall population analyses. Estimates of variance components within a breed were derived only for populations with purebred sires and dams. 
Table 2. Number of sires and dams with calves by breed

\begin{tabular}{lrr}
\hline \hline Breed & Sires & Dams \\
\hline Angus & 313 & 2,475 \\
Galloway & 30 & 0 \\
Hereford & 300 & 1,851 \\
Red Poll & 42 & 386 \\
Charolais & 181 & 1,022 \\
Shorthorn & 25 & 0 \\
Gelbvieh & 147 & 804 \\
Simmental & 103 & 1,187 \\
Norwegian/Swedish Red & 30 & 0 \\
Longhorn & 28 & 0 \\
Salers & 27 & 0 \\
Braunvieh & 50 & 414 \\
Belgian blue & 25 & 0 \\
Limousin & 66 & 372 \\
Pinzgauer & 56 & 290 \\
Piedmontese & 31 & 0 \\
Friesian & 24 & 0 \\
Brahman & 47 & 0 \\
Nellore & 22 & 0 \\
Boran & 8 & 0 \\
Tuli & 9 & 0 \\
MARC I & 165 & 1,417 \\
MARC II & 155 & 1,592 \\
MARC III & 173 & 4,697 \\
\hline
\end{tabular}

\section{Descriptive Statistics}

Descriptive statistics included overall BRD incidence by year and by age of calf, and unadjusted means by germplasm group for BRD incidence and associated mortality. The general effect of BRD on calf weaning weight was estimated by using the GLM procedure of SAS (SAS Inst., Inc, Cary, NC). Data were limited to calves that survived to weaning $(\mathrm{n}=31,243)$ and were either healthy (no recorded disease code) or diagnosed with BRD. The model included fixed effects for breed, year of record, sex of calf, age of dam, calving difficulty code, and health code (healthy vs. BRD). Age at weaning was included as a linear covariate. Differences in weaning weight between healthy and diagnosed calves were tested using Tukey's multiple comparison procedure. The effect of calving difficulty on BRD incidence also was examined. Percentage of calves with BRD and means for age when BRD was diagnosed were compared for different calving difficulty scores.

The hypothesis that calves with lighter birth weights may be more prone to BRD was tested using GENMOD procedures. Adjusted calf birth weights were used to prevent breed comparisons adjusted to a birth weight of zero. Birth weights were deviated from the overall mean birth weight for adjustment. The effect of adjusted birth weight was analyzed using linear and curvilinear covariates, and as interactions of linear or curvilinear covariates with germplasm group. Fixed effects included germplasm group and year of record-age of dam-sex of calf code. Because the response variable had a binomial distribution (healthy vs. sick), a logistic regression was performed. The significance of adjusted birth weight (linear and curvilinear) on incidence of
BRD was tested using Wald statistics for Type 3 contrasts.

\section{Germplasm Groups}

Variance components were initially estimated for each pure breed and the MARC I, II, and III composite breeds ( $\mathrm{n}=59,719)$. Relationship coefficients were created from all available pedigree information between 1968 and 2002 for each breed. Variance components were estimated using single-trait models with a derivative-free REML algorithm (Graser et al., 1987) with the computer programs of Boldman et al. (1995). Convergence was considered to have been reached when the variance of the $-2 \log \mathrm{L}$ in the simplex was less than $1 \times 10^{-6}$. After initial convergence, four restarts were performed to ensure global convergence as determined when the -2 logL did not change to the second decimal. Standard errors of heritability estimates were based on the average information matrix and the "delta" method (e.g., Dodenhoff et al., 1998). Fixed effects in the model included year-age of dam-sex of calf code subclasses and calving difficulty code (1 to 7). Julian date of birth and birth weight were included as covariates. Random effects included the calf (genetic direct), permanent environmental effect of the dam, and the maternal genetic effect of the dam. Three different models were compared (full and two reduced models) to determine the most appropriate model for each breed. The permanent environmental effect of the dam was deleted in the first reduced model (R1). In the second reduced model (R2), the permanent environmental and maternal genetic effects of the dam were both deleted. Reduced models were compared with the full model by a likelihood test with $-2 \log \mathrm{L}$ expressed as a deviation. The most appropriate model was identified as having the largest likelihood or a reduced model with a likelihood not significantly different from the full model.

Contrasts between solutions for breeds were tested with a Student's $t$-test. The Angus breed, having the largest breed registry in the United States, was chosen as the reference breed for comparison of solutions.

Data from all purebred and composite breeds also were combined into an overall analysis. The full model was similar to the previously described model for individual breeds, with the addition of a fixed effect for germplasm type of calf. Three additional reduced models were used to examine more closely the genetic correlation between the calf and maternal genetic effects, and to determine the most appropriate model. The first reduced model (R1) omitted the permanent environmental effect of the dam on her calves. The second reduced model (R2) contained only the calf (direct genetic) effect. The third reduced model (R3) was similar to the full model but constrained the covariance of the calf and maternal genetic effects to be zero.

Analyses of the second and larger data set compared the full, R1, and R2 models. This data set included 12 additional sire breeds (Shorthorn, Galloway, Piedmont- 
Table 3. Numbers, means, and ranges of breed fractions for calves and dams

\begin{tabular}{|c|c|c|c|c|c|c|}
\hline \multirow[b]{2}{*}{ Breed $^{a}$} & \multicolumn{3}{|c|}{ Calves } & \multicolumn{3}{|c|}{ Dams } \\
\hline & No. & Mean & Range & No. & Mean & Range \\
\hline ANG & 40,492 & 0.38 & 0.01 to 1.00 & 38,158 & 0.47 & 0.02 to 1.00 \\
\hline HER & 36,535 & 0.34 & 0.02 to 1.00 & 34,385 & 0.42 & 0.03 to 1.00 \\
\hline GAL & 475 & 0.35 & 0.25 to 0.50 & 306 & 0.50 & 0.50 \\
\hline SHO & 438 & 0.35 & 0.25 to 0.50 & 262 & 0.50 & 0.50 \\
\hline RED & 18,397 & 0.27 & 0.03 to 1.00 & 15,805 & 0.27 & 0.06 to 1.00 \\
\hline CHA & 10,824 & 0.52 & 0.25 to 1.00 & 7,505 & 0.55 & 0.25 to 1.00 \\
\hline LIM & 5,515 & 0.39 & 0.25 to 1.00 & 5,297 & 0.39 & 0.25 to 1.00 \\
\hline SAL & 551 & 0.33 & 0.25 to 0.50 & 367 & 0.50 & 0.50 \\
\hline SIM & 11,704 & 0.47 & 0.13 to 1.00 & 7,943 & 0.53 & 0.13 to 1.00 \\
\hline GEL & 8,660 & 0.48 & 0.01 to 1.00 & 7,627 & 0.50 & 0.03 to 1.00 \\
\hline PIN & 17,535 & 0.24 & 0.03 to 1.00 & 16,051 & 0.28 & 0.06 to 1.00 \\
\hline FRI & 677 & 0.37 & 0.25 to 0.50 & 361 & 0.50 & 0.50 \\
\hline BRV & 5,249 & 0.38 & 0.03 to 1.00 & 5,209 & 0.38 & 0.06 to 1.00 \\
\hline NSR & 605 & 0.37 & 0.25 to 0.50 & 305 & 0.50 & 0.50 \\
\hline PIE & 846 & 0.35 & 0.13 to 0.50 & 510 & 0.50 & 0.25 to 0.50 \\
\hline BEL & 1,057 & 0.36 & 0.25 to 0.50 & 595 & 0.50 & 0.50 \\
\hline LON & 560 & 0.33 & 0.06 to 0.50 & 367 & 0.48 & 0.13 to 0.50 \\
\hline BRA & 939 & 0.36 & 0.25 to 0.50 & 513 & 0.50 & 0.50 \\
\hline NEL & 534 & 0.34 & 0.25 to 0.50 & 345 & 0.50 & 0.50 \\
\hline BOR & 966 & 0.37 & 0.25 to 0.50 & 520 & 0.50 & 0.50 \\
\hline TUL & 1,068 & 0.36 & 0.25 to 0.50 & 579 & 0.50 & 0.50 \\
\hline
\end{tabular}

${ }^{\mathrm{a} A N G}=$ Angus; HER = Hereford GAL = Galloway; SHO = Shorthorn; RED = Red Poll; CHA = Charolais; LIM = Limousin; SAL = Salers; SIM = Simmental; GEL = Gelbvieh; PIN = Pinzgauer; FRI = Friesian; $\mathrm{BRV}=$ Braunvieh; NSR = Norwegian/Swedish Red; PIE = Piedmontese $; \mathrm{BEL}=$ Belgian Blue; LON = Longhorn; BRA = Brahman; NEL = Nellore; BOR = Boran; TUL = Tuli.

ese, Friesian, Norwegian/Swedish Red, Belgian Blue, Salers, Longhorn, Brahman, Nellore, Boran, and Tuli) represented only in composite populations. Breed fractions for calves and dams were calculated from pedigree information and ranged from zero to one (Table 3). For the 12 additional breeds, the breed fractions for the calves ranged from 0.25 to 0.50 , but all of their dams were $\mathrm{F}_{1}$ with breed fractions of 0.50 .

Breed effects on disease incidence were estimated using a single-trait model after convergence of variance components with a derivative-free REML algorithm. The model included fixed effects for calving difficulty score and the three-way subclass for year of record, sex of calf, and age of dam. Julian date of birth, breed fractions for calf and dam, and heterozygosity fractions (see below) for calf and dam were included as linear covariates. Random effects included the direct genetic of calf and maternal genetic of the dam. The MARC I, II, and III composites were not included because they were accounted for in the breed and heterozygosity fractions. Breed-specific solutions were contrasted pairwise between breeds. Because of partial confounding with heterozygosity type, solutions for the tropically adapted breeds (Brahman, Nellore, Boran, and Tuli) could not be contrasted with solutions for British and Continental breeds. Therefore, tropically adapted breeds were contrasted among themselves with the solution for the Brahman breed constrained to zero. The Angus breed was constrained to zero for comparison of British and Continental breeds. Solutions were contrasted for breeds of calf, breeds of dam, and for calf plus dam.

\section{Effect of Heterozygosity}

Heterozygosity fractions for calves and dams were calculated from a modified pedigree file. Pedigrees of all crossbred animals were traced back to purebred ancestors. Heterozygosity fractions ranging from 0 to 1 were then calculated for each animal $(n=71,140)$ in the pedigree file. Heterozygosity types were defined by generalized breed origins: British (Bos taurus), Continental (Bos taurus), and tropically adapted (Bos indicus and African Sanga). British breeds included Black and Red Angus, Hereford, Galloway, Red Poll, and Shorthorn. Continental breeds included Belgian Blue, Braunvieh, Charolais, Friesian, Gelbvieh, Limousin, Longhorn, Norwegian and Swedish Red, Piedmontese, Pinzgauer, Salers, and Simmental. Tropically adapted breeds included Bos indicus breeds (Boran, Brahman, and Nellore) and the Tuli, an African Sanga breed.

Heterozygosity types for calves and dams were British-British, British-Continental, British-Tropical, Continental-Continental, and Continental-Tropical. Tropically adapted breeds were not crossed; heterozygosity fractions did not exist within tropically adapted breeds. Crossbred and composite breed animals with three or more breeds in their heritage could have two or more different heterozygosity types; consider for example a Brahman sired calf from a Charolais-Hereford dam.

The effect of type of heterozygosity on disease incidence was evaluated using the model previously described for breed fractions by including heterozygosity type as a regression variable. Solutions for the regres- 


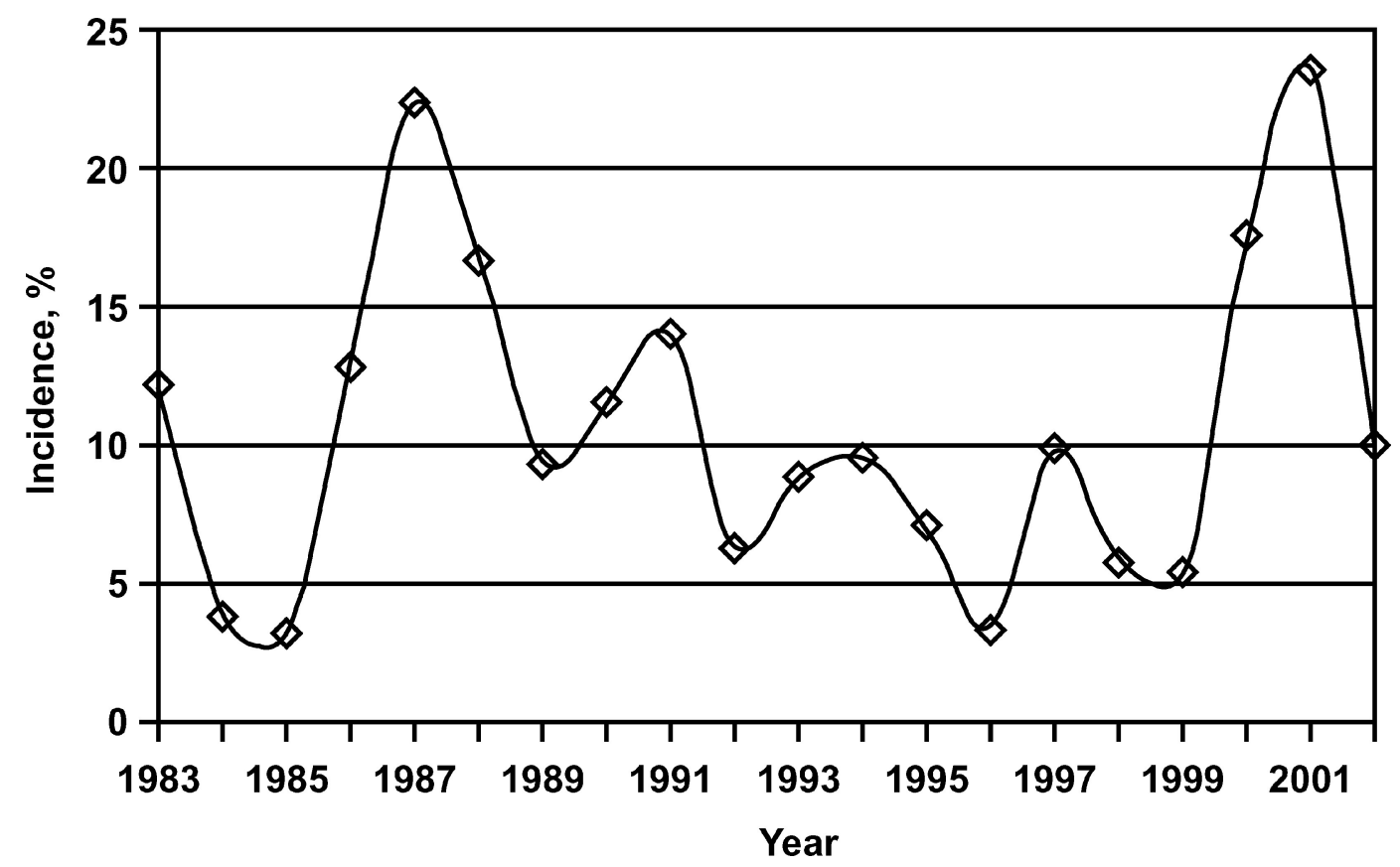

Figure 1. Incidence rates by year of bovine respiratory disease in preweaned beef calves from 1983 to 2001.

sion coefficients for heterozygosity type by calf and dam were contrasted against zero (purebreds) and among types of heterozygosity. Contrasts also were calculated using the sum of the regression coefficients for direct and maternal heterozygosity types contrasted with zero (purebreds) and among summed heterozygosity types.

\section{Effect of Incidence}

The larger data set of all purebred and crossbreds was divided into six smaller data sets based on annual average BRD incidences (Figure 1). Three data sets included years of low BRD incidence (low 2 yr of 1985 and 1996; low $3 \mathrm{yr}$ of 1984, 1985, and 1996; and low 12 yr of 1984, 1985, 1992 to 1999, and 2002). Three data sets included years of high BRD incidence (high $2 \mathrm{yr}$ of 1987 and 2001; high 4 yr of 1987, 1988, 2000, and 2001; and high 8 yr of 1983, 1986 to 1988, 1990, 1991, 2000, and 2001). The single-trait animal model was identical to the full model described for evaluating the effect of heterozygosity but did not include a permanent environmental effect of the dam or a maternal genetic effect. In preliminary analyses, the permanent environmental and maternal genetic effect had estimated variances of zero. The broken data structure resulted in many of the dams' records not being in the same data set as their progeny's records. Estimation of the maternal genetic component was difficult because dam-progeny pairs of records were not available to separate the direct and maternal genetic variances. This may have inflated the direct variance estimate; however, this was assumed to be a negligible effect based on the very small estimates for the maternal genetic variance in previous models. Estimates of variance components with all six models were compared to approximate the effect of BRD incidence on estimates of variance components.

\section{Results and Discussion}

The use of field data to estimate genetic factors associated with diseases has obvious limitations. Distinguishing between the phenotypes of healthy vs. sick animals is not always accurate. Animals infected with the same disease may express different clinical symptoms and may vary in degree of expression. The number of animals exposed to the disease depends on the epidemic level, which fluctuates with the degree of disease challenge. Therefore, disease-free animals may be healthy because they were not exposed or not sufficiently exposed to disease organisms. In addition, a disease may result from a secondary infection rather than from a primary infection, so that resistance to a disease may partially depend on resistance to the primary disease. The influence of passive immunity on disease occurrence, such as colostral antibody dosage, is generally unknown for many diseases. Passive immunity has been shown to be effective in protecting calves from respiratory infection (Howard et al., 1989; Belknap et al., 1991). Diseases that are time-, age-, or season-dependent, or transitional over time may not be accurately detected in all susceptible populations. Moreover, because not all animals will be equally exposed to the disease-causing organism under most field conditions, the underlying genetic variation may be greater than the variation observed for disease resistance (Dempster and Lerner, 1950).

Because animal movements across pasture groups were not well recorded, it was not possible to account 


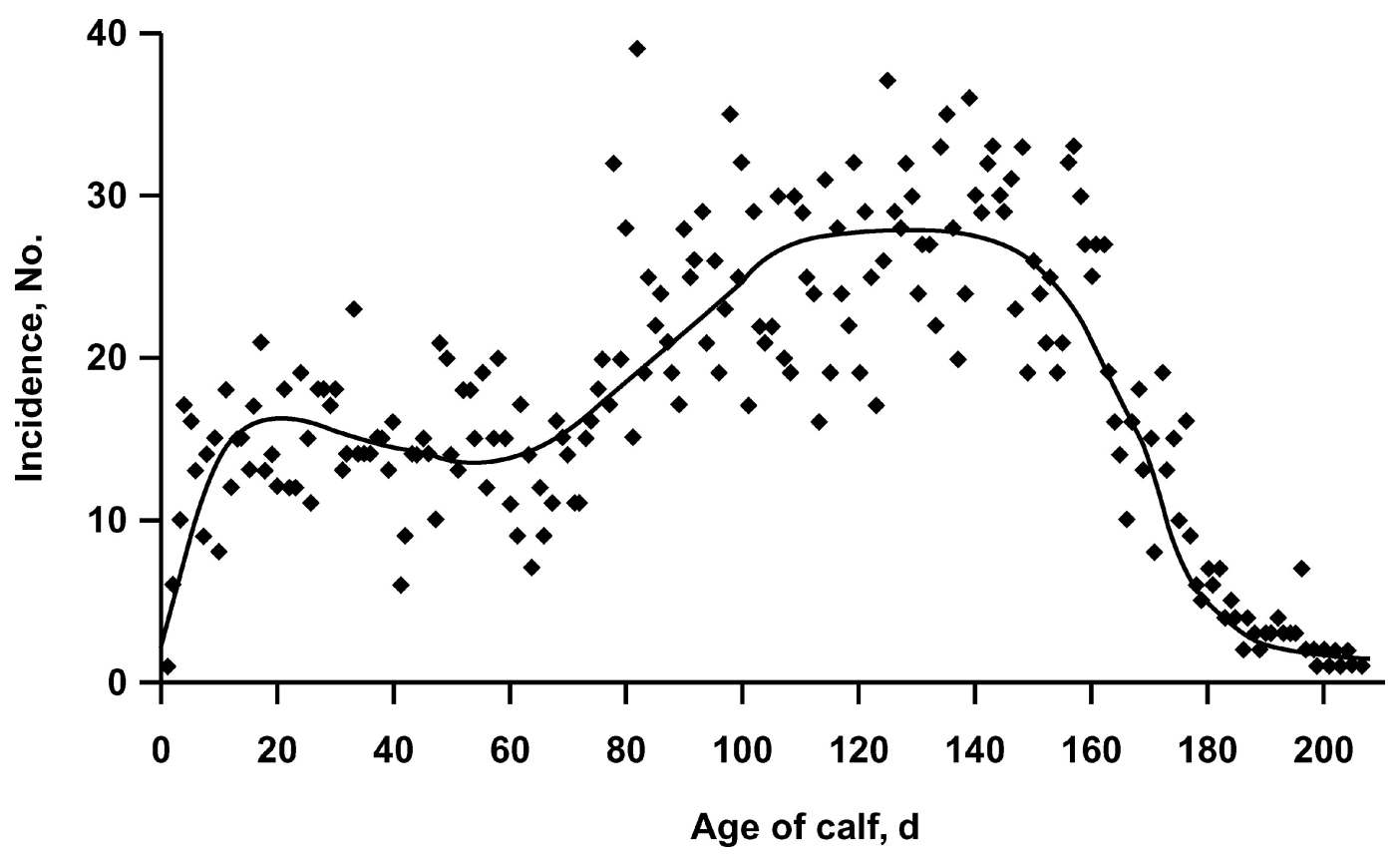

Figure 2. Number of calves diagnosed with bovine respiratory disease by day of age diagnosed.

for spatial and temporal clustering effects accurately. Clusters of diseases can occur within a group, pasture, herd, or region. Statistical analysis of disease clustering is often included in epidemiological research (Carpenter, 2001). A previous study showed that clustering of mastitis-causing pathogens can have a significant effect on the estimated variance components of repeated records within a herd and cow (van Dorp et al., 2002). This potential bias may be important when considering differences among adjusted breed means. The REML analysis partially accounts for clustering effects by considering contemporary groups, which averages out the effects of year and pastures from the sire effect. The estimated genetic parameters from REML procedures would not be expected to be greatly influenced by clustering. Nonetheless, the effect of spatial and temporal clustering on variance estimation for disease traits needs further investigation.

\section{Characteristics of $B R D$}

The incidence of BRD within this herd varied across the 20-yr span (Figure 1) and ranged from 3.3 to $23.6 \%$ / yr, with an average annual incidence of $10.5 \%$. Specific environmental factors could not be attributed to years with high incidence $(1987,1988,2000$, and 2001) that would distinguish them from years with low incidence (1984, 1985, 1996, 1998, and 1999).

The number of calves diagnosed per day with BRD was associated with age of calf (Figure 2). Shortly after birth, the number of calves diagnosed with BRD per day increased and remained generally constant, ranging from 10 to 20 calves/d until approximately $75 \mathrm{~d}$ of age, when the incidence typically ranged from 20 to 34 calves/d. At approximately $170 \mathrm{~d}$ of age, the incidence decreased sharply to less than 10 calves/d. The greater incidence between 75 and $170 \mathrm{~d}$ of age may be partially attributed to increased commingling of animals during the breeding season when cows were frequently gathered for AI.

The plotted trend for daily BRD incidence also may depict the epidemiological phases of BRD. Models of microparasitic infections (Anderson and May, 1992) have shown that a stable endemic equilibrium of the infection rate can occur when the contact rate between animals susceptible to the disease and infectious animals does not reach above a certain threshold. From Figure 2, there seem to be two periods of increasing BRD transmission rate ( 0 to 20 , and 70 to $100 \mathrm{~d}$ of age). Each of these two periods was followed by a period of endemic equilibrium (20 to 70 , and 100 to $150 \mathrm{~d}$ of age). The final phase or recovery period when the transmission rate decreased occurred after $150 \mathrm{~d}$ of age. Epidemiological studies of these phases may lead to management alternatives to decrease BRD incidence.

The average age (days) at which BRD was diagnosed differed among breeds (Table 4 ), with the youngest average age observed in the Simmental breed ( $68 \mathrm{~d}$ ). Four breeds were intermediate to the other breeds for average age of first diagnosis: Pinzgauer ( $80 \mathrm{~d}$ ), Charolais and Limousin ( $87 \mathrm{~d}$ ), and Braunvieh ( $88 \mathrm{~d}$ ). The average age for other breeds ranged from 99 to $111 \mathrm{~d}$.

Birth weight did not influence incidence of BRD. When all germplasm groups were considered, the effects of linear and curvilinear covariates for adjusted birth weights were not important $(P=0.87$ and 0.93 , respectively); however, the effect of birth weight within a breed on BRD incidence was not further investigated in this study. 
Table 4. Number of records, average age when bovine respiratory disease (BRD) diagnosed, incidence rate of BRD, mortality among calves with BRD, and death loss resulting from BRD among all calves by breed and overall

\begin{tabular}{lrrccc}
\hline \hline Group & No. & Age, d & Incidence, \% & Mortality, \% & Total death, \% \\
\hline Angus & 6,347 & 111.3 & 9.97 & 14.5 & 1.4 \\
Hereford & 4,579 & 106.8 & 8.34 & 12.4 & 1.0 \\
Red Poll & 998 & 102.5 & 9.22 & 16.0 & 1.5 \\
Charolais & 2,878 & 87.0 & 11.64 & 14.3 & 1.7 \\
Simmental & 1,775 & 68.2 & 10.87 & 17.7 & 1.9 \\
Limousin & 961 & 87.7 & 11.86 & 7.0 & 1.0 \\
Gelbvieh & 2,391 & 105.6 & 9.79 & 10.1 & 1.6 \\
Pinzgauer & 908 & 80.0 & 10.57 & 15.6 & 1.8 \\
Braunvieh & 907 & 87.6 & 18.85 & 10.4 & 1.7 \\
MARC I & 4,336 & 103.8 & 16.67 & 11.9 & 1.0 \\
MARC II & 4,959 & 103.7 & 8.69 & 17.2 & 1.7 \\
MARC III & 10,947 & 99.0 & 9.70 & 13.1 & 1.4 \\
Overall & 41,986 & 100.8 & 10.52 & \\
\hline
\end{tabular}

${ }^{\text {a }}$ Mortality included calves that died or were culled for reasons associated with BRD.

The general economic effect of BRD on calf production can be inferred by the effects on weaning weight and calf death loss. All fixed effects in the linear model to examine the effect of BRD on weaning weight were significant, with the model accounting for $78 \%$ of the variation. Calves diagnosed with BRD were $7.7 \mathrm{~kg}$ lighter $(P<0.001)$ than healthy calves (least squares means of $258.47 \pm 0.39 \mathrm{~kg}$ and $251.71 \pm 0.51 \mathrm{~kg}$, respectively) at weaning. With an average annual incidence rate of $10.5 \%$ (Table 4), the loss in weaning weight would be economically significant, especially to producers marketing calves at weaning. The overall calf death loss attributed to BRD was $1.4 \%$ (Table 4) of all calves. In the MARC herd, BRD was the leading cause of illness and death among preweaned calves. Although total prevention of BRD seems unlikely, reduction of BRD incidence would be economically advantageous when costs of intervention do not exceed loss in production. The total economic loss associated with preweaned calf pneumonia in this herd was previously estimated at $\$ 50.46$, not including labor, per sick calf, or $\$ 2.83$ per calf cost (Dewell et al., 2002).

Calves from births requiring major assistance were more susceptible to BRD, and those that expressed BRD were younger at diagnosis than calves born with little or no calving difficulty (score less than 4 ; Table 5). These findings infer that calves subject to increased trauma during birth would benefit from additional care to prevent BRD. Calves born by caesarean surgery ( score $=7$ ) had a lower incidence of BRD, and those that expressed BRD were older at diagnosis compared with calves requiring major assistance of more than $30 \mathrm{~min}$ at birth (score $=6)$.

\section{Effect of Germplasm Groups}

Breed differences were found for incidence, mortality (death), and total death loss (Table 4). The highest incidence rates were for Braunvieh (19\%) and MARC I (17\%), which is a $1 / 4$ Braunvieh composite. The high incidence of BRD in Braunvieh may be confounded with the breed's higher incidence of calving difficulty, especially in 2-yr-old dams (Gregory et al., 1991a). Incidence rate ranged from 8 to $12 \%$ for other groups. The highest mortality rates among calves diagnosed with BRD were in the Simmental (18\%), MARC III (17\%), and Red Poll (16\%) breeds. Lowest mortality rates were for Limousin (7\%) and Braunvieh (9\%). Although the highest incidence of BRD was observed in the Braunvieh, the mortality rate among Braunvieh cattle was much less than the overall average of $13 \%$. The high mortality rate among MARC III calves with BRD (17\%) and the relatively low incidence rate (10\%) suggest that MARC III calves are more sensitive to the disease, although more resistant to infection, than other breeds. Total death loss among all calves was least (approximately 1\%) for Limousin, Hereford, Gelbvieh, and MARC II, and greatest for Charolais, Simmental, Braunvieh, MARC I, and MARC III. The higher death loss in the Simmental may be related to their younger average age of incidence ( 68 d) compared with the overall average of $100 \mathrm{~d}$. Clinical expression of most diseases generally is more severe in younger animals. A difference in mortality rates among breeds suggests a possible genetic diversity in immune

Table 5. Number of calves born by calving difficulty score, percentage expressing bovine respiratory disease (BRD), and least squares means for average age when BRD detected

\begin{tabular}{lrrr}
\hline \hline Score & \multicolumn{1}{c}{ No. } & BRD & Age, d \\
\hline 1 & 52,298 & 8.6 & $106^{\mathrm{x}}$ \\
2 & 527 & 7.2 & $89^{\mathrm{xy}}$ \\
3 & 2,617 & 9.9 & $85^{\mathrm{xy}}$ \\
4 & 2,592 & 13.3 & $74^{\mathrm{y}}$ \\
5 & 789 & 12.7 & $74^{\mathrm{y}}$ \\
6 & 124 & 19.4 & $59^{\mathrm{z}}$ \\
7 & 775 & 14.6 & $78^{\mathrm{y}}$ \\
\hline
\end{tabular}

${ }_{\mathrm{x}, \mathrm{y}, \mathrm{z} \text { Within the age column, means without a common superscript }}$ letter differ, $P<0.05$. 
Table 6. Numbers of animals in the pedigree file, numbers of inbred animals, and average inbreeding coefficient $(\mathrm{F})$ of inbred animals by breed

\begin{tabular}{lrrr}
\hline \hline Breed & Total & Inbred & F, \% \\
\hline Angus & 7,327 & 278 & 2.6 \\
Hereford & 5,837 & 236 & 3.4 \\
Red Poll & 1,178 & 171 & 3.8 \\
Charolais & 3,281 & 1,075 & 1.6 \\
Gelbvieh & 2,617 & 825 & 2.0 \\
Simmental & 2,213 & 125 & 3.1 \\
Braunvieh & 1,118 & 69 & 4.0 \\
Limousin & 1,153 & 78 & 3.4 \\
Pinzgauer & 1,059 & 137 & 3.9 \\
MARC I & 4,691 & 1,017 & 1.7 \\
MARC II & 5,517 & 1,120 & 2.2 \\
MARC III & 12,547 & 1,853 & 2.6 \\
\hline
\end{tabular}

responses among these breeds. Breed differences in age when infected, incidence rates, and mortality rates for BRD are large and should be considered for health management protocols and breed selection.

The number of calves for each pure or composite breed ranged from 1,059 to 12,547 (Table 6). Over $45 \%$ of all calves were MARC composites. Because breeding schemes were specifically designed to maintain low coefficients of inbreeding, numbers of inbred animals and average inbreeding coefficients were relatively low. The highest percentage of inbred animals (33\%) was in the Charolais breed, but the average inbreeding coefficient for inbred animals was low (1.6\%). The low number of inbred animals and/or low inbreeding coefficients infer that inbreeding did not greatly affect estimates of variance for any of the breeds.

Estimates of variance components for the pure and composite breeds were affected by choice of models (Table 7). For each breed, at least one reduced model was not significantly different from the full model. Because the estimated variances for the permanent environmental effect of the dam for all breeds ranged from zero to low, and because the reduced models without this effect did not differ from the full model, this effect was implied not to be important for resistance to BRD. This conclusion suggests the dams' influence on the overall environment, which includes environmental portions of maternal ability, milk production, and passive immunity protection as influenced by previous exposure events, had little effect on resistance of the calf to BRD.

The direct genetic effect on incidence of BRD was not large. Estimates of heritability ranged from 0.00 to 0.26 With the R2 model, which was determined to be appropriate for most breeds (except for Angus, Hereford, Pinzgauer, MARC I, and MARC III), estimates of heritability ranged from 0.00 to 0.04 . Low estimates of heritability may be partially related to the measurement error of disease detection or the large variation in the clinical expression of BRD. In a previous study involving steers from birth to slaughter at MARC, only $50 \%$ of the animals with pulmonary lesions at slaughter had been previously detected with BRD (Wittum et al., 1996). However, the frequency and severity of lesions were not characterized, so subclinical infections were not differentiated from clinical infections by Wittum et al. (1996).

The maternal genetic component generally was not an important effect for incidence of $\mathrm{BRD}$, with estimates of maternal heritability ranging from 0.00 to 0.12 . Maternal genetic variance was significant only for Angus, Hereford, Pinzgauer, MARC I, and MARC III; however, the differences in -2logL between the full and R2 models were not always large. Lower heritability estimates of the direct effect in the R2 models compared with the full and R1 models suggest the maternal genetic component was not confounded with the direct effect or that the data structure did not allow for proper separation of the variances.

Estimates of the genetic correlation between direct and maternal genetic effects were generally similar between the full and R1 models. Most estimates were either equal to or approximately 1.00 or -1.00 . For breeds where the maternal genetic component was equal to zero or not significant, the estimated genetic correlation will be unreliable. For the Angus, Hereford, Pinzgauer, MARC I, and MARC III composite breeds, where the maternal genetic component was significant, the genetic correlations between the direct and maternal effects were large and negative $\left(r_{g}=-0.90,-0.97\right.$, $-0.87,-0.71$, and -0.98 , respectively). Because most female calves diagnosed with BRD or that were healthy were retained in the herd and had progeny with their own BRD record, the data structure seems reliable for estimating a direct-by-maternal genetic correlation. Nonetheless, large genetic correlations may indicate something else in the data structure is inadequate for estimating the genetic correlation.

A large and negative genetic correlation infers that dams genetically superior for helping their calves resist BRD will produce calves susceptible to BRD. One explanation may be that a dam's increased maternal genetic ability to produce and/or sustain production of immunoglobulins for BRD and to transmit these via lactation may delay the development of the calf's own immune system, thereby increasing the calf's susceptibility to $\mathrm{BRD}$ at a later age. A large negative genetic correlation between direct and maternal genetic effects might suggest some degree of maternally imprinted major gene influencing BRD resistance is present.

The solutions for Braunvieh and MARC I calves differed from most other breeds $(P \leq 0.05$; Table 8$)$ and inferred that they have higher incidences of BRD. Because the MARC I is a $1 / 4$ Braunvieh composite, its higher incidence may be partially influenced by the Braunvieh genetic contribution. The large negative solutions for Braunvieh and MARC I agreed with their observed higher incidences of BRD (19 and 17\%, respectively; Table 4). Although we previously suggested that the high incidence of BRD in the Braunvieh may be associated with its higher rate of calving difficulty com- 
Table 7. Comparison of models for estimating variance components for resistance to bovine respiratory disease (BRD) in pure and composite breeds

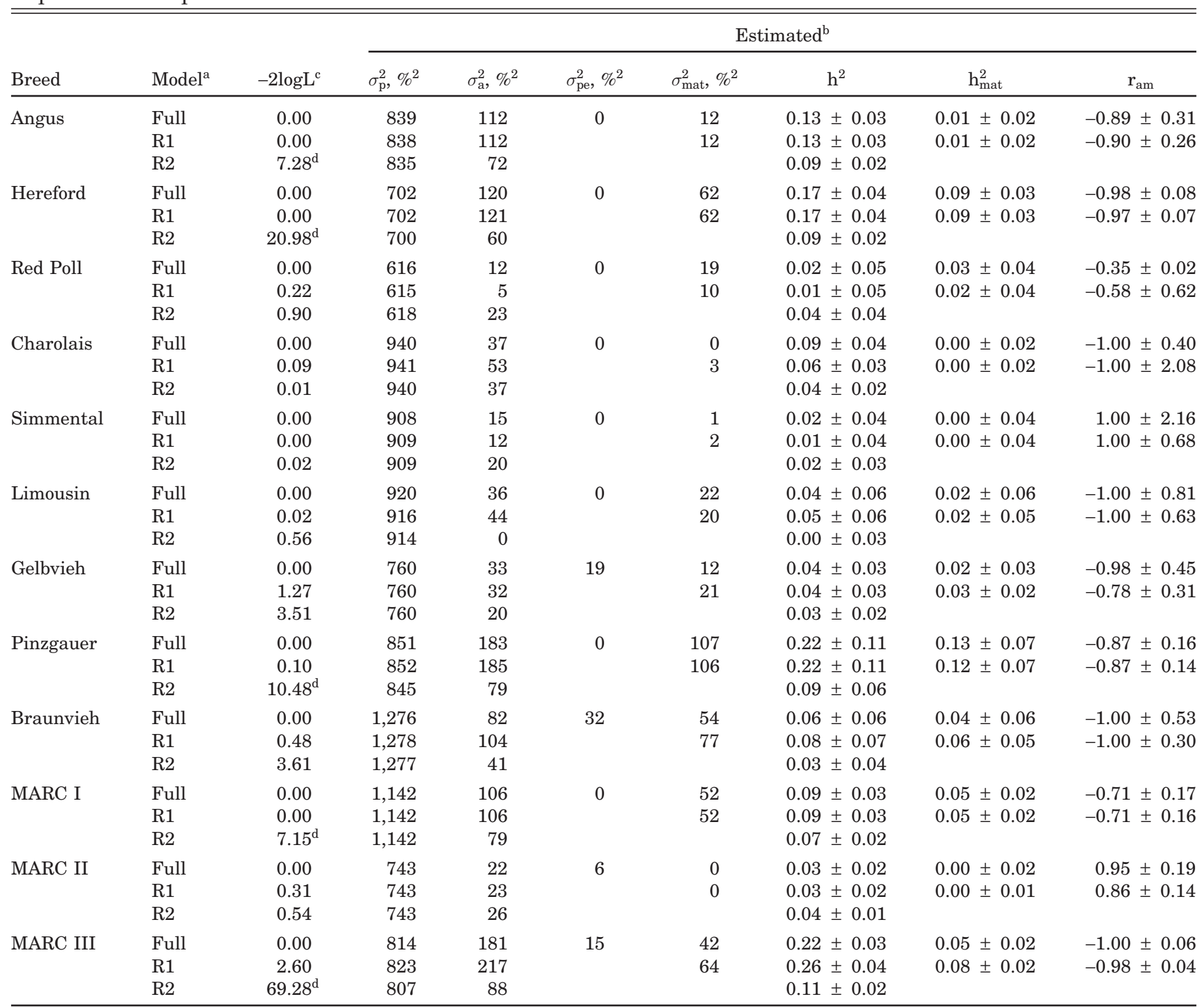

${ }^{\mathrm{a}}$ Full model includes $\sigma_{\mathrm{a}}^{2}, \sigma_{\mathrm{mat}}^{2}, \sigma_{\mathrm{pe}}^{2}$, and $\operatorname{cov}_{\mathrm{a} \text {,mat }} ; \mathrm{R} 1$ includes $\sigma_{\mathrm{a}}^{2}, \sigma_{\mathrm{mat}}^{2}$, and $\operatorname{cov}_{\mathrm{a} \text {,mat }} ; \mathrm{R} 2$ includes $\sigma_{\mathrm{a}}^{2}$.

${ }^{\mathrm{b}} \sigma_{\mathrm{p}}^{2}=$ phenotypic variance; $\sigma_{\mathrm{a}}^{2}=$ additive genetic variance; $\sigma_{\mathrm{pe}}^{2}=$ maternal permanent environmental variance; $\sigma_{\mathrm{mat}}^{2}=$ maternal genetic variance; $h^{2}=$ heritability estimate; $h_{\text {mat }}^{2}=$ maternal heritability estimate; $r_{a m}=$ genetic correlation of direct and maternal genetic effects.

${ }^{\mathrm{c}}$ Difference in $-2 \log$ likelihoods from full model within breed group.

d_2logL is significantly different from full model within germplasm group, $P<0.05$.

pared with all other breeds and composites, this association cannot be applied to the MARC I because the incidence of calving difficulty in the MARC I was similar to that of other breeds (Gregory et al., 1991a). The MARC II composite with one of the lowest observed incidences (9\%) had the largest positive solution (favorable) and differed from 7 of the 11 other breeds. British breeds did not differ among themselves, and within the Continental breeds, only the Braunvieh differed among them.

Results of the overall analyses of purebred and composite groups were more definitive (Table 9) than individual breed results. The maternal permanent environ- mental effect was small but significant because the $-2 \log \mathrm{L}$ differed between the full and R1 models. The heritability estimate of the maternal genetic effect also was small $(0.06 \pm 0.01)$ and significant in the full model. Constraining the covariance of calf and maternal genetic effects to zero did not improve variance estimates for the maternal genetic effect (Model R3). The large negative genetic correlations between the calf and maternal genetic effects in the full and R1 models were significant and agreed with estimates for Angus, Hereford, Pinzgauer, MARC I, and MARC III breeds.

The most appropriate model for the larger data set (germplasm utilization study of purebreds and compos- 
Table 8. Solutions by germplasm group and $t$-values for pairwise breed contrasts for incidence of bovine respiratory disease

\begin{tabular}{lcccccccccccc}
\hline \hline Group $^{\mathrm{a}}$ & Solution $^{\mathrm{b}}$ & HER & RED & BRV & SIM & LIM & CHA & GEL & PIN & M1 & M2 & M3 \\
\hline ANG & 0.00 & 0.05 & 1.55 & $3.30^{*}$ & 0.77 & 0.23 & 1.17 & 1.23 & 0.55 & $3.52^{*}$ & $2.64^{*}$ & 0.04 \\
HER & 0.06 & & 1.53 & $3.36^{*}$ & 0.82 & 0.27 & 1.22 & 1.20 & 0.52 & $3.58^{*}$ & $2.62^{*}$ & 0.00 \\
RED & 3.13 & & & $3.77^{*}$ & 1.94 & 1.42 & $2.19^{*}$ & 0.17 & 0.75 & $3.71^{*}$ & 0.16 & 1.41 \\
BRV & -6.23 & & & & $2.49^{*}$ & $2.39^{*}$ & $2.17^{*}$ & $3.72^{*}$ & $2.90^{*}$ & 0.75 & $4.92^{*}$ & $3.05^{*}$ \\
SIM & -1.10 & & & & & 0.31 & 0.36 & 1.70 & 1.00 & $2.29^{*}$ & $2.94^{*}$ & 0.69 \\
LIM & -0.45 & & & & & & 0.59 & 1.10 & 0.62 & $2.11^{*}$ & 1.94 & 0.24 \\
CHA & -1.70 & & & & & & & 2.00 & 1.26 & 1.88 & $3.26^{*}$ & 1.04 \\
GEL & 2.03 & & & & & & & & 0.37 & $3.82^{*}$ & 0.82 & 1.07 \\
PIN & 1.15 & & & & & & & & & $2.70^{*}$ & 1.07 & 0.49 \\
M1 & -4.74 & & & & & & & & & & $5.61^{*}$ & $3.04^{*}$ \\
M2 & 3.46 & & & & & & & & & & & $2.19^{*}$ \\
M3 & 0.06 & & & & & & & & & & & \\
\hline
\end{tabular}

$* P \leq 0.05$.

${ }^{\mathrm{a} A N G}=$ Angus $;$ HER = Hereford $;$ RED = Red Poll; BRV = Braunvieh; SIM = Simmental $;$ LIM = Limousin; CHA = Charolais; GEL = Gelbvieh; PIN = Pinzgauer; M1 = MARC I; M2 = MARC II; M3 = MARC III.

bolutions are expressed as a difference from the solution for Angus.

ites, and germplasm evaluation study with crossbreds) was $\mathrm{R} 1$, which omitted the permanent environmental effect of the dam because the estimate of variance was zero (Table 10). When compared with the previously analyzed germplasm utilization data set (Table 9), estimates of phenotypic and direct variances (761 and 172 , respectively) were smaller, and the heritability estimate of $0.22 \pm 0.01$ agreed with those estimated by the full and R1 models in the germplasm utilization study.

Tests of contrasts of solutions of tropically adapted breeds with other breeds were not possible because the expected values of those contrasts included only contrasts among other effects in addition to breed effects. Therefore, solutions for tropically adapted breeds were tested, but not with solutions for British and Continental breeds.

Differences in the incidence of BRD among calves of British and Continental breeds were detected (Table 11). Large positive solutions (favorable) were obtained for Red Poll, Salers, Longhorn, Shorthorn, and Gallo- way breeds. These breeds did not differ among themselves for incidence of BRD, but they differed from most other breeds. Friesian calves were significantly more likely to have BRD infection compared with calves from most other breeds. Angus and Hereford breeds, the two most popular U.S. breeds, did not have higher incidences of BRD than other breeds, but they had lower incidences of BRD than the Friesian breed.

Calves from tropically adapted breeds were not significantly different for BRD infection from each other (Table 12). Although the solution for Nellore crosses was large and positive (8.4), pairwise comparisons with Nellore had large standard errors, ranging from 5.0 to 6.3 , such that differences were not statistically significant.

Few differences were detected among breed influence of dam (Tables 11 and 12). Calves reared by $\mathrm{F}_{1}$ Red Poll dams had significantly higher BRD infection compared with most breeds of dam (Limousin, Simmental, Friesian, and Belgian Blue). Calves reared by Friesian

Table 9. Comparison of models to estimate variance components for incidence of bovine respiratory disease in overall populations of purebred and composite groups

\begin{tabular}{|c|c|c|c|c|c|c|c|c|c|}
\hline \multirow[b]{2}{*}{ Model $^{\mathrm{a}}$} & \multirow[b]{2}{*}{$-2 \log L^{c}$} & \multicolumn{8}{|c|}{ Estimated $^{b}$} \\
\hline & & $\sigma_{\mathrm{p}}^{2}, \%^{2}$ & $\sigma_{\mathrm{a}}^{2}, \%^{2}$ & $\sigma_{\mathrm{pe}}^{2}, \%^{2}$ & $\sigma_{\text {mat }}^{2}, \%^{2}$ & $\operatorname{Cov}_{a, m a t}$ & $\mathrm{~h}^{2}$ & $\mathrm{~h}_{\text {mat }}^{2}$ & $\mathrm{r}_{\mathrm{am}}$ \\
\hline Full & 0.0 & 898 & 183 & 0 & 53 & -93 & $0.20 \pm 0.01$ & $0.06 \pm 0.01$ & $-0.94 \pm 0.03$ \\
\hline $\mathrm{R} 1$ & $73.4^{\mathrm{d}}$ & 902 & 199 & & 53 & -99 & $0.22 \pm 0.01$ & $0.06 \pm 0.01$ & $-0.93 \pm 0.02$ \\
\hline R2 & $215.9^{\mathrm{d}}$ & 893 & 93 & & & & $0.10 \pm 0.01$ & & \\
\hline R3 & $215.9^{\mathrm{d}}$ & 893 & 93 & 0 & 0 & 0 & $0.10 \pm 0.01$ & $0.00 \pm 0.01$ & 0.00 \\
\hline \multicolumn{10}{|c|}{ 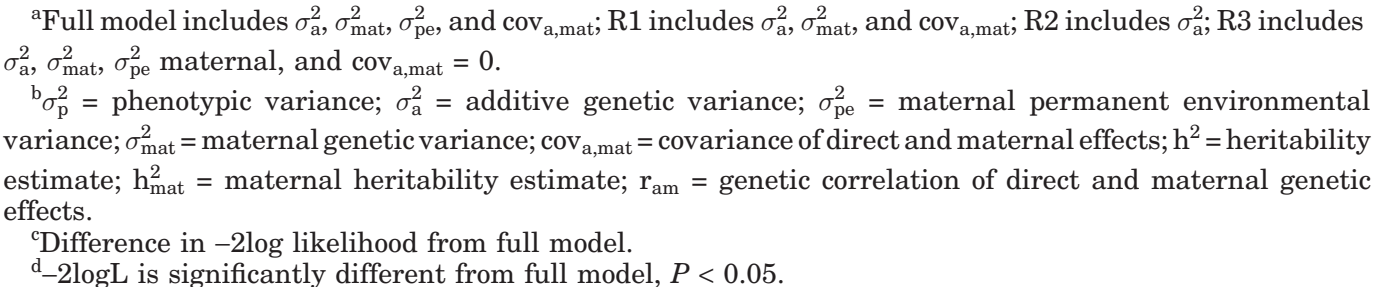 } \\
\hline
\end{tabular}


Table 10. Comparison of models to estimate variance components for incidence of bovine respiratory disease with combined populations of purebred, composite, and crossbred groups

\begin{tabular}{|c|c|c|c|c|c|c|c|c|c|}
\hline \multirow[b]{2}{*}{ Model $^{\mathrm{a}}$} & \multirow[b]{2}{*}{$-2 \log \mathrm{L}^{\mathrm{c}}$} & \multicolumn{8}{|c|}{ Estimated $^{\mathrm{b}}$} \\
\hline & & $\sigma_{\mathrm{p}}^{2}, \%^{2}$ & $\sigma_{\mathrm{a}}^{2}, \%^{2}$ & $\sigma_{\mathrm{pe}}^{2}, \%^{2}$ & $\sigma_{\text {mat }}^{2}, \%^{2}$ & $\operatorname{Cov}_{a, \text { mat }}$ & $\mathrm{h}^{2}$ & $\mathrm{~h}_{\text {mat }}^{2}$ & $\mathrm{r}_{\mathrm{am}}$ \\
\hline Full & 0.00 & 766 & 172 & 0 & 51 & -88 & $0.22 \pm 0.01$ & $0.07 \pm 0.01$ & $-0.95 \pm 0.02$ \\
\hline $\mathrm{R} 1$ & 0.00 & 761 & 172 & & 51 & -88 & $0.22 \pm 0.01$ & $0.07 \pm 0.01$ & $-0.95 \pm 0.02$ \\
\hline $\mathrm{R} 2$ & $365^{\mathrm{d}}$ & 761 & 87 & & & & $0.11 \pm 0.02$ & & \\
\hline
\end{tabular}

${ }^{a}$ Full model includes $\sigma_{\mathrm{a}}^{2}, \sigma_{\text {mat }}^{2}, \sigma_{\mathrm{pe}}^{2}$ maternal, and $\operatorname{cov}_{\mathrm{a}, \mathrm{mat}} ; \mathrm{R} 1$ includes $\sigma_{\mathrm{a}}^{2}, \sigma_{\text {mat }}^{2}$, and cova,mat; R2 includes $\sigma_{\mathrm{a}}^{2}$.

${ }^{\mathrm{b}} \sigma_{\mathrm{p}}^{2}=$ phenotypic variance; $\sigma_{\mathrm{a}}^{2}=$ additive genetic variance; $\sigma_{\mathrm{pe}}^{2}=$ maternal permanent environmental variance; $\sigma_{\text {mat }}^{2}=$ maternal genetic variance; $\operatorname{cov}_{\mathrm{a}, \text { mat }}=$ covariance of direct and maternal effects; $\mathrm{h}^{2}=$ heritability estimate; $\mathrm{h}_{\mathrm{mat}}^{2}=$ maternal heritability estimate; $\mathrm{r}_{\mathrm{am}}=$ genetic correlation between direct and maternal genetic effects.

'Difference in -2log likelihood from full model.

d_-2logL is significantly different from full model, $P<0.05$.

Table 11. Solutions by breed of calf, dam, and calf plus dam (Total) for incidence of bovine respiratory disease and results of pairwise comparisons (within columns) among British and Continental breeds

\begin{tabular}{lrrrrrr}
\hline \hline Breed $^{\mathrm{a}}$ & Calf $^{\mathrm{b}}$ & $t$-test & Dam $^{\mathrm{b}}$ & $t$-test & Total $^{\mathrm{b}}$ & $t$-test \\
\hline BRV & -2.29 & & -5.48 & & -7.77 & $\mathrm{j}$ \\
CHA & -0.25 & $\mathrm{c}$ & -1.13 & $\mathrm{~g}$ & -1.38 & $\mathrm{k}$ \\
LIM & -7.50 & $\mathrm{~d}$ & 6.16 & & -1.34 & $\mathrm{l}$ \\
NSR & -3.76 & $\mathrm{~d}$ & 2.64 & & -1.12 & \\
SIM & -3.73 & $\mathrm{~d}$ & 2.94 & & -0.79 & $\mathrm{l}$ \\
FRI & -9.70 & $\mathrm{e}$ & 8.92 & & -0.78 & \\
HER & -1.17 & $\mathrm{c}$ & 0.41 & & -0.77 & $\mathrm{~m}$ \\
PIN & 3.04 & & -3.22 & $\mathrm{~g}$ & -0.18 & \\
ANG & 0.00 & $\mathrm{f}$ & 0.00 & & 0.00 & $\mathrm{n}$ \\
BEL & -5.59 & $\mathrm{~d}$ & 6.21 & & 0.62 & \\
GEL & 0.35 & & 1.91 & & 2.26 & \\
RED & 8.33 & & -4.82 & $\mathrm{~h}$ & 3.50 & \\
PIE & 3.06 & & 1.55 & & 4.60 & \\
SAL & 8.33 & & -2.18 & $\mathrm{i}$ & 6.15 & \\
LON & 7.98 & & -1.68 & & 6.29 & \\
SHO & 9.05 & & -0.77 & & 8.28 & \\
GAL & 11.22 & & -2.19 & & 9.03 & \\
\hline
\end{tabular}

${ }^{\mathrm{a}} \mathrm{BRV}=$ Braunvieh $;$ CHA = Charolais LIM = Limousin $;$ NSR = Norwegian/Swedish Red; SIM = Simmental; FRI = Friesian; HER = Hereford; PIN = Pinzgauer; ANG = Angus; BEL = Belgian Blue; GEL = Gelbvieh; RED = Red Poll; PIE = Piedmontese SAL = Salers; $\mathrm{LON}=$ Longhorn; $\mathrm{SHO}=$ Shorthorn; GAL = Galloway .

${ }^{\text {b }}$ Solutions are expressed as a deviation from the solution for Angus.

'Different from RED, SHO, and GAL, $P<0.05$.

${ }^{\mathrm{d}}$ Different from LON, RED, SAL, SHO, and GAL, $P<0.05$.

${ }^{\mathrm{e}}$ Different from CHA, ANG, GEL, PIN, PIE, LON, RED, SAL, SHO, and GAL, $P<0.05$.

fDifferent from RED, and GAL, $P<0.05$.

gDifferent from BEL and FRI, $P<0.05$.

${ }^{\mathrm{h}}$ Different from SIM, LIM, BEL and FRI, $P<0.05$.

${ }^{\mathrm{i} D i f f e r e n t}$ from FRI, $P<0.05$.

'Different from CHA, LIM, HER, PIN, ANG, GEL, RED, PIE, SAL,

LON, SHO, SIM, and GAL, $P<0.05$.

${ }^{\mathrm{k} D i f f e r e n t}$ from GEL, RED, and GAL, $P<0.05$.

${ }^{\mathrm{l}}$ Different from RED and GAL, $P<0.05$.

${ }^{\mathrm{m}}$ Different from RED, GAL, and LON, $P<0.05$.

${ }^{\mathrm{n}}$ Different from RED, $P<0.05$. crossbred dams had significantly lower incidences of BRD than calves reared by Red Poll, Charolais, Salers, or Pinzgauer crossbred dams. Significant differences were not detected among calves with tropically adapted breeds of $\mathrm{F}_{1}$ dams (Table 12).

The signs of solutions for calf and dam breed fractions (Table 11) were reversed for all British and most Continental breeds, except for Gelbvieh, Braunvieh, and Piedmontese. This result agrees with the negative genetic correlations between the calf and maternal genetic effects reported from the variance component analyses in this study. Possibly, the previously described negative relationship between the effective passive immunity caused by the dam and later-stage susceptibility of the calf could be a cause for the change in signs for breed effects.

When breed of calf and dam solutions were added together (Tables 11 and 12), most breeds did not differ significantly for BRD incidence, except for the Braunvieh, which was significantly different (negative) from most other breeds. The Galloway and Red Poll breeds, with positive calf and dam solutions, were significantly different from a few other breeds. Although this study did not clearly identify any breed(s) with total superiority in resisting $\mathrm{BRD}$, a single breed, the Braunvieh, may have been identified as having a greater susceptibility for BRD.

Table 12. Solutions for calves, dams, and calf plus dam (total) for incidence of respiratory disease for tropically adapted breeds

\begin{tabular}{lrrr}
\hline \hline Breed & Calf $^{\mathrm{a}}$ & Dam $^{\mathrm{a}}$ & Total $^{\mathrm{a}}$ \\
\hline Tuli & -0.36 & -1.49 & -1.85 \\
Brahman & 0.00 & 0.00 & 0.00 \\
Boran & 0.10 & 0.53 & 0.63 \\
Nellore & 8.44 & -3.06 & 5.38 \\
\hline
\end{tabular}

aSolutions are expressed as a deviation from the solution for Brahman. 
Table 13. Number of crossbred animals and means and ranges of direct and maternal hyterozygosity values by crossbred type

\begin{tabular}{llrrr}
\hline \hline Type & Effect & No. & Mean, \% & Range, \% \\
\hline British-British & Direct & 27,944 & 34.9 & 0.1 to 100.0 \\
British-Continental & Direct & 36,390 & 51.3 & 1.6 to 100.0 \\
British-Tropical & Direct & 2,247 & 77.9 & 37.5 to 100.0 \\
Continental-Continental & Direct & 16,225 & 30.8 & 0.4 to 100.0 \\
Continental-Tropical & Direct & 2,166 & 40.6 & 12.5 to 62.5 \\
British-British & Maternal & 25,709 & 36.0 & 3.1 to 100.0 \\
British-Continental & Maternal & 28,024 & 49.5 & 3.1 to 100.0 \\
British-Tropical & Maternal & 2,044 & 89.8 & 37.5 to 100.0 \\
Continental-Continental & Maternal & 10,765 & 27.4 & 0.8 to 62.5 \\
Continental-Tropical & Maternal & 917 & 22.8 & 12.5 to 62.5 \\
\hline
\end{tabular}

\section{Effect of Heterozygosity}

Numbers of crossbred calves and maximum and minimum heterozygosity fractions varied among breed types (Table 13). Tropically adapted types were least represented and had the smallest range of heterozygosity fractions. Maternal heterozygosity values for Continental $\times$ Continental crosses were limited to a maximum of $62.5 \%$ and an overall mean of $27 \%$. British types crossed with other British and Continental types were well represented and had a large range of heterozygosity fractions. Most British $\times$ Tropically adapted crosses were $\mathrm{F}_{1}$ crosses, as indicated by the high mean heterozygosity fraction of $90 \%$. Extrapolation of statistical estimates beyond the experimental range in heterozygosity fractions may be questionable. The range and means of direct and maternal heterozygosity fractions for Continental $\times$ Tropically adapted crosses differed because of breeding schemes (40.6 vs. $22.8 \%$, respectively).

The incidence of BRD was significantly less in all crossbreds due to calf heterozygosity (positive solutions) compared with purebreds (zero heterozygosity; Table 14). British $\times$ Continental or Tropically adapted

Table 14. Solutions by heterozygosity type of calf, dam, and calf plus dam (total) for incidence of respiratory disease and results of pairwise comparisons (within columns) among heterozygosity types

\begin{tabular}{lllrcrc}
\hline \hline Type $^{\mathrm{a}}$ & Calf $^{\mathrm{b}}$ & $t$-test & Dam $^{\mathrm{b}}$ & $t$-test & Total $^{\mathrm{b}}$ & $t$-test \\
\hline CC & 6.27 & & -14.86 & $\mathrm{c}$ & -8.59 & $\mathrm{c}$ \\
CT & 7.86 & & -7.85 & & -0.01 & \\
Pure & 0.00 & $\mathrm{~d}$ & 0.00 & $\mathrm{e}$ & 0.00 & $\mathrm{f}$ \\
BB & 4.30 & $\mathrm{~g}$ & -1.94 & & 2.36 & $\mathrm{~g}$ \\
BC & 6.77 & & -1.68 & & 5.09 & \\
BT & 8.67 & & -0.75 & & 7.92 & \\
\hline
\end{tabular}

${ }^{\mathrm{a}} \mathrm{CC}=\mathrm{Continental} /$ Continental $; \mathrm{CT}=\mathrm{Continental} /$ Tropical $;$ Pure $=$ Purebred, zero heterozygosity; $\mathrm{BB}=\mathrm{British} / \mathrm{British}$; $\mathrm{BC}=\mathrm{British} /$ Continental; BT $=$ British/Tropical.

${ }^{b}$ Solutions are expressed as a deviation from the solution for purebred.

${ }^{\mathrm{c}}$ Different from Pure, BB, BC, and BT, $P<0.05$.

${ }^{\mathrm{d}}$ Different from CC, CT, BB, BC, and BT, $P<0.05$.

${ }^{\mathrm{e} D i f f e r e n t}$ from BB, $P<0.05$.

fDifferent from CC, BB, BC, and BT, $P<0.05$.

${ }^{\mathrm{g} D i f f e r e n t}$ from $\mathrm{BC}$ and $\mathrm{BT}, P<0.05$. calf types of heterozygosity had a lower incidence of BRD than British $\times$ British crosses. Effects of calf heterozygosity for crosses within Continental or Tropically adapted types did not differ in BRD incidence.

Increased heterozygosity of the dam had an increasingly negative effect on BRD incidence (Table 14) compared with purebred dams (Table 11). Dams with Continental $\times$ Continental heterozygosity fractions had significantly more calves diagnosed with BRD than purebred and crossbred dams, except for dams from Continental $\times$ Tropically adapted breeds.

Solutions for calf and solutions for maternal heterozygosity type were added to estimate an overall combining ability for a type of breed cross (Table 14). Such a sum generally does not reflect a real breeding plan because breed composition of the dam usually will vary from that of its calf, especially for production systems that optimize heterosis. The sum may reflect an overall score for the type of heterozygosity and may mitigate possible partial confounding of calf and dam heterozygosity types. Overall, British crossbreds would have a lower incidence of BRD compared with purebred populations; however, British $\times$ Continental or Tropically adapted breed crosses would have an even lower overall incidence of BRD than British $\times$ British crosses. Because of the large negative effect due to heterozygosity type of the dam, Continental $\times$ Continental crosses would have a greater incidence of BRD than purebreds and British crosses. Calves with British $\times$ Tropically adapted breed type of heterozygosity would have a decreased incidence of BRD than purebreds and British $\times$ British and Continental $\times$ Continental crosses. Overall, calves and dams with Continental $\times$ Tropically adapted breed type heterozygosity would have no advantage in decreasing the incidence of BRD compared with purebreds and other heterozygosity types.

\section{Effect of Incidence}

As incidence of BRD increased, there was an associated increase in the estimated phenotypic and direct variances (Table 15). During years of low incidence (less than $7 \%$ ), the estimated phenotypic and additive variances were at least twofold smaller than estimates for 
Table 15. Average incidence of bovine respiratory disease, number of observations and variance component estimates by groups of years with differing incidence levels ${ }^{\mathrm{a}}$

\begin{tabular}{lrrrrrr}
\hline \hline Group & Avg, $\%$ & \multicolumn{1}{c}{ No. } & $\sigma_{\mathrm{p}}^{2}, \%^{2}$ & $\sigma_{\mathrm{a}}^{2}, \%^{2}$ & $\sigma_{\mathrm{pe}}^{2}, \%^{2}$ & \multicolumn{1}{c}{$\mathrm{h}^{2}$} \\
\hline Low 3 yr & 3.6 & 8,645 & 336 & 42 & 0 & $0.11 \pm 0.02$ \\
Low 6 yr & 4.7 & 18,652 & 401 & 32 & 0 & $0.08 \pm 0.01$ \\
Low 12 yr & 6.9 & 37,015 & 528 & 30 & 0 & $0.06 \pm 0.01$ \\
High 8 yr & 16.4 & 22,704 & 1,089 & 133 & 0 & $0.12 \pm 0.01$ \\
High 4 yr & 20.1 & 10,801 & 1,267 & 234 & 0 & $0.18 \pm 0.02$ \\
High 2 yr & 23.0 & 4,814 & 1,587 & 403 & 0 & $0.25 \pm 0.04$ \\
\hline
\end{tabular}

${ }^{\mathrm{a}} \sigma_{\mathrm{p}}^{2}=$ phenotypic variance; $\sigma_{\mathrm{a}}^{2}=$ additive genetic variance; $\sigma_{\mathrm{pe}}^{2}=$ maternal permanent environmental variance; $h^{2}=$ heritability estimate.

years with high BRD incidence (greater than $16 \%$ ). Estimates of heritability remained low, ranging from 0.06 to 0.11 , during years of low incidence, but estimates increased during years of high incidence, ranging from 0.12 to 0.25 . Comparison of these models based on incidence of BRD infers that not all animals were challenged with BRD infection during low years, and that during years of high BRD incidence, there is a greater opportunity for expression of genetic resistance to BRD.

Because BRD incidence is a dichotomous threshold trait, it is reasonable to assume there is an underlying scale of genetic variation (Robertson and Lerner, 1949). Estimated heritability on the observed scale can be transformed into a heritability estimate on the underlying continuous scale (Robertson's appendix to Dempster and Lerner, 1950). The heritability for incidence of BRD for the underlying continuous scale was estimated to be 0.48 using the heritability estimate of 0.20 (Table 9 ), and the overall annual average BRD incidence of $10.5 \%$ (Table 4). Because the heritability estimate for the underlying continuous scale is notably larger than the estimate for the observed scale, selection for BRD could be effective provided all animals are challenged adequately with the disease. Thus, development of an inexpensive and humane method of challenging animals for BRD resistance would seem an important step in decreasing the incidence of BRD.

Although BRD is a disease of concern for biosecurity because of its widespread incidence in cattle (Callan and Garry, 2002), BRD can be controlled by decreasing pathogen transmission between animals. Management practices that decrease pathogen introduction, exposure, and transmission are important initial steps; however, because total eradication of BRD pathogens is not likely, decreasing pathogen transmission between animals can be achieved by removing affected animals and avoiding crowding. Another approach is to decrease the number of susceptible animals by increasing the number of BRD resistant or tolerant animals. This can be achieved by the use of vaccines or antibiotics; however, some pathogens may be resistant to antibiotics, and the efficacy of vaccines may be limited. Vaccines can be very effective in decreasing not only susceptibility but also reducing shedding of infectious BRD agents to other calves (Frank et al., 1994, 2003). Antibiotics will not make the animal resistant, but they can decrease carriage and shedding of $M$. haemolytica (Frank et al., 2000, 2002). Another approach is to select for individuals resistant or tolerant to BRD. All animals in a population need not be resistant to prevent an epidemic; rather, a sufficient number of animals resistant to the disease needs to be present to decrease its spread among susceptible animals (Anderson and May, 1992; Bishop and MacKenzie, 2003).

Pathogens of BRD in this study were assumed to be not of a single variety, but rather of bacterial, viral, and/or mycoplasmal origin. If this assumption is correct, then selection for $\mathrm{BRD}$ resistance or tolerance may gradually result in an improved generalized disease defense mechanism, possibly a more efficacious immune system. Previous studies have demonstrated that antibody and/or cell-mediated immune responses could be used to improve health and production in cattle (Hernández et al., 2003), swine (Mallard et al., 1992, 1998), and poultry (Sarke et al., 2000). Further investigations into the genetic mechanisms of disease resistance are certainly warranted.

The results of the study do not suggest the presence of a strong clustering effect. Because only a single breed (Braunvieh) differed significantly from all other breeds for BRD incidence, and because the Braunvieh population was commingled with several other breeds over many years, it is logical to assume that temporal and/ or spatial clustering effects, if present, were small.

\section{Implications}

New approaches to decreasing disease epidemics are needed to replace or complement current vaccination and antibiotic regimens. This study contributes to our knowledge of environmental and genetic factors influencing bovine respiratory disease. The population characteristics and epidemiological pattern described herein should be useful for the prevention and management of respiratory disease. Moreover, beef cattle producers are provided with estimates of genetic differences among breeds for disease incidence to consider for breed selection. The positive influence of heterozygosity for decreasing the disease incidence in preweaned calves demonstrates that crossbreeding decreases dis- 
ease incidence. Although the estimated observed heritability for incidence of respiratory disease was low, the estimated underlying heritability was large $\left(h^{2}=0.48\right)$, suggesting a favorable response to selection for disease resistance. Future research should determine how best to identify the phenotype of resistant animals.

\section{Literature Cited}

Anderson, R. M., and R. M. May. 1992. Infectious Diseases of Humans. Dynamics and Control. Oxford Univ. Press, Oxford, U.K.

Belknap, E. B., J. C. Baker, J. S. Patterson, R. D. Walker, D. M. Haines, and E. G. Clark. 1991. The role of passive immunity in bovine respiratory syncytial virus-infected calves. J. Infect. Dis. 163:470-476.

Bishop, S. C., and K. M. MacKenzie. 2003. Genetic management strategies for controlling infectious diseases in livestock populations. Genet. Sel. Evol. 35(Suppl. 1):S3-S17.

Boldman, K. G., L. A. Kriese, L. D. Van Vleck, C. P. Van Tassell, and S. D. Kachman. 1995. A Manual for Use of MTDFREML. A set of programs to obtain estimates of variances and covariances. USDA, ARS, Clay Center, NE.

Callan, R. J., and F. B. Garry. 2002. Biosecurity and bovine respiratory disease. Vet. Clin. North Am. Food Anim. Pract. 18:57-77.

Carpenter, T. E. 2001. Methods to investigate spatial and temporal clustering in veterinary epidemiology. Prev. Vet. Med. 48:303-320.

Cundiff, L. V., K. E. Gregory, and R. M. Koch. 1998. Germplasm evaluation in beef cattle-Cycle IV: Birth and weaning traits. J. Anim. Sci. 76:2528-2535.

Cundiff, L. V., T. L. Wheeler, S. D. Shackelford, M. Koohmaraie, R. M. Thallman, K. E. Gregory, and L. D. Van Vleck. 2001. Preliminary results from cycle VI of the cattle Germplasm Evaluation Program at the Roman L. Hruska U.S. Meat Animal Research Center. Prog. Rep. No. 20. Available: http//www. marc.usda.gov. Accessed Feb. 15, 2005.

Dempster, E. R., and I. M. Lerner. 1950. Heritability of threshold characters. Genetics 35:212-236.

Dewell, G. A., J. E. Keen, Dewell, R. D., W. W. Laegreid, and L. L. Hungerford. 2002. Production and financial losses associated with pre-weaning disease in beef cattle. Abstr. No. 31 in Proc. Res. Workers in Anim. Dis. Conf., St. Louis, MO.

Dodenhoff, J., L. D. Van Vleck, S. D. Kachman, and R. M. Koch. 1998. Parameter estimates for direct, maternal and grandmaternal genetic effects for birth weight and weaning weight in Hereford cattle. J. Anim. Sci. 76:2521-2527.

Ellis, J. A. 2001. The immunology of the bovine respiratory disease complex. Vet. Clin. North Am. Food Anim. Pract. 17:535-549.

Frank, G. H., R. E. Briggs, G. C. Duff, and H. S. Hurd. 2003. Effect of intranasal exposure to eukotoxin-deficient Mannheimia haemolytica at the time of arrival at the feedyard on subsequent isolation of M. haemolytica from nasal secretions of calves. Am. J. Vet. Res. 64:580-585.

Frank, G. H., R. E. Briggs, G. C. Duff, R. W. Loan, and C. W. Purdy. 2002. Effects of vaccination prior to transit and administration of florfenicol at time of arrival in a feedlot on the health of transported calves and detection of Mannheimia haemolytica in nasal secretions. Am. J. Vet. Res. 63:251-256.

Frank, G. H., R. E. Briggs, R. W. Loan, C. W. Purdy, and E. S. Zehr. 1994. Serotype-specific inhibition of colonization of the tonsils and nasoharynx of calves after Pasteurella haemolytica serotype A1 vaccination with the organism. Am. J. Vet. Res. 55:11071110 .

Frank, G. H., R. E. Briggs, R. W. Loan, C. W. Purdy, and E. S. Zehr. 2000. Effects of tilmicosin treatment on Pasteurella haemolytica organisms in nasal secretion specimens of calves with respiratory tract disease. Am. J. Vet. Res. 61:525-529.

Freetly, H. C., and L. V. Cundiff. 1997. Postweaning growth and reproduction characteristics of heifers sired by bulls of seven breeds and raised on different levels of nutrition. J. Anim. Sci. 75:2841-2851.

Graser, H. U., S. P. Smith, and B. Tier. 1987. A derivative-free approach for estimating variance components in animal models by restricted maximum likelihood. J. Anim. Sci. 64:1362-1370.

Gregory, K. E., L. V. Cundiff, and R. M. Koch. 1991a. Breed effects and heterosis in advanced generations of composite populations for birth weight, birth date, dystocia, and survival as traits in beef cattle. J. Anim. Sci. 69:3574-3589.

Gregory, K. E., L. V. Cundiff, and R. M. Koch. 1991b. Breed effects and heterosis in advanced generations of composite populations for preweaning traits of beef cattle. J. Anim. Sci. 69:947-960.

Gregory, K. E., L. V. Cundiff, and R. M. Koch. 1999. Composite breeds to use heterosis and breed differences to improve efficiency of beef production. USDA Tech. Bull. No. 1875. USDA, ARS, Clay Center, NE.

Hernández, A., N. Karrow, and B. A. Mallard. 2003. Evaluation of immune responses of cattle as a means to identify high or low responders and use of a human microarray to differentiate gene expression. Genet. Sel. Evol. 35(Suppl. 1):S67-S81.

Howard, C. J., M. C. Clarke, and J. Brownlie. 1989. Protection against respiratory infection with bovine virus diarrhea virus by passively acquired antibody. Vet. Microbiol. 19:195-203.

Mallard, B. A., B. N. Wilkie, B. W. Kennedy, J. Gibson, and M. Quinton. 1998. Immune responsiveness in swine: Eight generations of selection for high and low immune response in Yorkshire pigs. Proc. 6th World Cong. Genet. Appl. Livest. Prod., Armidale, Australia XXVII:257-262.

Mallard, B. A., B. N. Wilkie, B. W. Kennedy, and M. Quinton. 1992. Use of estimated breeding values in a selection index to breed Yorkshire pigs for high and low immune and innate resistance factors. Anim. Biotechnol. 3:257-280.

Muggli-Cockett, N. E., L. V. Cundiff, and K. E. Gregory. 1992. Genetic analysis of bovine respiratory disease in beef calves during the first year of life. J. Anim. Sci. 70:2013-2019.

NAHMS. 1997. Part II. Reference of 1997 beef cow-calf health and heath management practices. USDA, APHIS, National Animal Health Monitoring System. Available: http://www. aphis.usda. gov/vs/ceah/cahm/Beef_Cow-Calf/beef.htm. Accessed Nov. 20, 2003.

Robertson, A., and I. M. Lerner. 1949. The heritability of all-or-none traits: viability of poultry. Genetics 34:395-411.

Sarke, N., M. Tsudzuki, M. Nishibori, H. Yasues, and Y. Yamamoto. 2000. Cell-mediated and humoral immunity and phagocytic ability in chicken lines divergently selected for serum immunoglobulin M and G levels. Poult. Sci. 79:1705-1709.

Smith, T. P., N. Lopez-Corrales, S. M. Kappes, and T. S. Sonstegard. 1997. Myostatin maps to the interval containing the bovine $\mathrm{mh}$ locus. Mamm. Genome 8:742-744.

Van Dorp, T. E., L. R. Schaeffer, P. Boettcher, D. Kelton, and M. M. Shoukri. 2002. Genetic selection programs for resistance to mastitis. Proc. 7th World Cong. Genet. Appl. Livest. Prod. Montpellier, France, No. 09-24.

Westell, R. A., R. L. Quaas, and L. D. Van Vleck. 1988. Genetic groups in an animal model. J. Dairy Sci. 71:1310-1318.

Wittum, T. E., N. E. Woollen, L. J. Perino, and E. T. Littledike. 1996. Relationships among treatment for respiratory tract disease, pulmonary lesions evident at slaughter and rate of weight gain in feedlot cattle. J. Am. Vet. Med. Assoc. 209:814-818.

Wheeler, T. L., L. V. Cundiff, S. D. Shackelford, and M. Koohmaraie. 2001. Characterization of biological types of cattle (Cycle V): Carcass traits and longissimus palatability. J. Anim. Sci. 79:1209-1222. 